\title{
Novel Thermal Curing Reactions of Epoxy Resin and Poly(glycidyl methacrylate) Using Photo-generated Difunctional Thiols
}

\author{
Tadatomi Nishikubo, ${ }^{\dagger}$ Atsushi Kameyama, Koutaro Kashiwagi, and Naoto Oyama \\ Department of Applied Chemistry, Faculty of Engineering, Kanagawa University, \\ Rokkakubashi, Kanagawa-ku, Yokohama 221, Japan
}

(Received March 6, 1996)

\begin{abstract}
Blocked dithiols such as $p$-xylenebis(2-nitrobenzyl- $\alpha$-S-thiocarbonate) (XBBTC) and bis[(2-nitrobenzyloxycarbonyl)thioethyl]ether (EBTE) were synthesized by reactions of 1,4-bis(mercaptomethyl)benzene (BMMB) and ethylene glycol bis(mercaptoethyl)ether (EBME) with $N$-(2-nitrobenzyloxycarbonyl)imidazole. The prepared XBBTC and EBTE decomposed very smoothly to the corresponding dithiol such as BMMB and EBME by irradiation with UV-light in tetrahydrofuran (THF) solution, epoxy resins, or polymer film. Thermal curing reaction of epoxy resins and poly(glycidyl methacrylate-co-methyl methacrylate) (PGMA) using photo-generated dithiols were also examined, and it was found that novolactype epoxy resin and PGMA gave gel products by heating with photo-generated dithiol compounds, although bisphenol type epoxy resin did not produce gel products by treatment under the same conditions. The ring opening reaction of the epoxide group in the mixture of epoxy compounds with blocked dithiols was confirmed by IR spectra.

KEY WORDS Synthesis of Blocked Dithiol / Photo-generation / Difunctional Thiol / Thermal Curing Reaction / Epoxy Resin / Poly(glycidyl methacrylate) /
\end{abstract}

Polyfunctional amines are very important reagents for the thermal curing reaction of epoxy resins, and this reaction system has been widely used ${ }^{1}$ for coatings, paints, adhesives, for sealing, packaging, and so on in industry. However, the storage stability at room temperatrure of mixtures of epoxy resins with amines has not been satisfactory, since the reaction of epoxy resins with polyfunctional amines proceed even at room temperature to give the corresponding insoluble addition products. Accordingly, the generation of polyfunctional free amines from the blocked amino groups by photo-irradiation followed by the thermal crosslinking reaction of epoxy resins using the generated polyfunctional amines are very important chemical processes in the industry. Winkle et al. ${ }^{2}$ reported the photogeneration of free amines from 2-nitrobenzyl carbamates by irradiation with UV light. Kutal et al. $^{3}$ studied photo-generation of ammonia from the reaction of a cobalt-amine complex. Tsunooka et al. ${ }^{4}$ also examined photo-generation of free amines from the reactions of $o$-acyloxyamines. Cameron et al. ${ }^{5}$ reported the photogeneration of polyfunctional free amines such as hexane1,6-diamine (HMDA) by the photochemical reaction of certain blocked polyfunctional amines. They used these reactions of photo-generated amines or polyfunctional amines with polymers containing epoxy groups for photo-resist technology. Recently, the authors reported ${ }^{6}$ the photo-generation of various polyfunctional free amines from certain blocked polyfunctional amine compounds followed by novel thermal curing reactions of epoxy resins and polyuretane oligomers.

Polyfunctional thiols are also very useful reagents, along with polyfunctional amines, for the thermal curing reaction of epoxy resins. ${ }^{1}$ However, the storage stability of mixtures of epoxy resins with polyfunctional thiols is insufficient at room temperature, since polyfunctional thiols have high chemical reactivity. There-

\footnotetext{
† To whom all correspondence should be addressed.
}

fore, the photo-generation ${ }^{7}$ of polyfunctional thiol compounds from the blocked thiol groups by irradiation with UV light and applications to the curative formulation of epoxy resins represent key advances in photopolymer chemistry. This paper reports the synthesis of blocked polyfunctional thiol compounds, photo-generation of polyfunctional thiol compounds, and thermal curing reaction of epoxy resins.

\section{EXPERIMENTAL}

\section{Materials}

Organic solvents were dried using $\mathrm{P}_{2} \mathrm{O}_{5}, \mathrm{CaH}_{2}$, or $\mathrm{Na}$ metal wire and purified in the usual way before use. Commercial epoxy resins such as Epicoat 828 (epoxide equivalent: 190) and DEN 438 (epoxide equivalent: 181) were used without further purification. Reagent grade $N, N^{\prime}$-carbonyldiimidazole, 2-nitrobenzyl alcohol, 1,4bis(mercaptomethyl)benzene (BMMB), and ethylene glycol bis(mercaptoethyl)ether (EBME) were also used without further purification. Poly(glycidyl methacrylateco-methyl methacrylate) containing a pendant epoxide group (epoxide equivalent: 181) PGMA $\left(M_{n}=30000\right)$ was synthesized by the radical copolymerization of glycidyl methacrylate $(70 \mathrm{~mol} \%)$ and methyl methacrylate (30 $\mathrm{mol} \%$ ) using $\alpha, \alpha^{\prime}$-azobisisobutyronitrile (AIBN) as an initiator in $N, N$-dimethylformamide (DMF) at $60^{\circ} \mathrm{C}$ for $12 \mathrm{~h}$ according to the reported method. ${ }^{8}$

\section{Measurement}

Infrared (IR) spectra were measured on a JASCO model IR-700 spectrometer. ${ }^{1} \mathrm{H}$ NMR spectra were recorded on JEOL models JNM EX-90 $(90 \mathrm{MHz})$ and JNM FX-200 (200 MHz) instruments in the deuterated solvents using $\mathrm{Me}_{4} \mathrm{Si}$ [tetramethylsilane (TMS)] as the internal standard. UV spectra were obtained on a Shimadzu model UV-2100S UV-VIS spectrophotometer. Molecular weights of the polymers were estimated by gel permeation chromatography (GPC) with the use 
of a model LC-909 GPC (Japan Analytical Industry Co., Ltd.) equipped with a refractive index detector using JAIGEL-1HA-F and JAIGEL-1H-A gel columns (eluent: THF, calibrated with narrow molecular weight polystyrene standards).

\section{Synthesis of $N$-(2-Nitrobenzyloxycarbonyl)imidazole}

The reaction of $10.7 \mathrm{~g}(70 \mathrm{mmol})$ of 2-nitrobenzyl alcohol with $11.4 \mathrm{~g}(70 \mathrm{mmol})$ of $N, N^{\prime}$-carbonyldiimidazole was carried out in acetonitrile $(280 \mathrm{~mL})$ at room temperature for $24 \mathrm{~h}$, and the solvent was evaporated in vacuo. The precipitated crude product was recrystallized from ethyl acetate. The yield of $N$-(2-Nitrobenzyloxycarbonyl)imidazole (NBCI) was $13.4 \mathrm{~g}(78 \%)$. mp $143-144^{\circ} \mathrm{C}$. IR $(\mathrm{KBr}): 1751(\mathrm{C}=\mathrm{O}), 1523$ and 1342 $\left(-\mathrm{NO}_{2}\right)$, and $1179 \mathrm{~cm}^{-1}(\mathrm{C}-\mathrm{O}-\mathrm{C})$. UV (in THF): $241 \mathrm{~nm}$. ${ }^{1} \mathrm{H}$ NMR (90 MHz, $\left.\mathrm{CDCl}_{3}, \mathrm{TMS}\right): \delta=5.8\left(\mathrm{~s}, 2 \mathrm{H}, \mathrm{CH}_{2}\right)$, $7.1-7.2(\mathrm{~m}, 1 \mathrm{H}, \mathrm{N}=\mathrm{CH}), 7.4-7.5,(\mathrm{~m}, 1 \mathrm{H}, \mathrm{N}=\mathrm{CH})$, $7.5-7.8(\mathrm{~m}, 3 \mathrm{H}$, aromatic protons $)$, and $8.1-8.2 \mathrm{ppm}$ ( $\mathrm{m}, 2 \mathrm{H}$, aromatic proton and $\mathrm{N}=\mathrm{CH}$ ).

Anal. Calcd for $\mathrm{C}_{11} \mathrm{H}_{9} \mathrm{~N}_{3} \mathrm{O}_{4}$ : C, $53.44 \% ; \mathrm{H}, 3.68 \%$; N, $17.00 \%$. Found: C, $53.33 \%$; H, 3.50\%; N, 17.16\%.

Synthesis of p-Xylenebis(2-nitrobenzyl- $\alpha$-S-thiocarbonate) $p$-Xylenebis(2-nitrobenzyl- $\alpha-S$-thiocarbonate) (XBBTC) was synthesized by reaction of $12.4 \mathrm{~g}(50$ mmol) of NBCI with $4.3 \mathrm{~g}(25 \mathrm{mmol})$ of BMMB in DMF $(250 \mathrm{~mL})$ at $50^{\circ} \mathrm{C}$ for $30 \mathrm{~min}$ under nitrogen, and the crude product was recrystallized from ethyl acetate. The yield of XBBTC was $9.2 \mathrm{~g}(70 \%)$. mp $139-140^{\circ} \mathrm{C}$. IR $(\mathrm{KBr}): 1709(\mathrm{C}=\mathrm{O}), 1518$ and $1338\left(-\mathrm{NO}_{2}\right)$, and 1136 $\mathrm{cm}^{-1}$ (C-O-C). UV (in THF): $260 \mathrm{~nm} .{ }^{1} \mathrm{H}$ NMR $(90$ $\left.\mathrm{MHz}, \mathrm{CDCl}_{3}, \mathrm{TMS}\right): \delta=4.1\left(\mathrm{~s}, 4 \mathrm{H}, \mathrm{S}-\mathrm{CH}_{2}\right), 5.7$ (s, $4 \mathrm{H}$, $\mathrm{CH}_{2}-\mathrm{O}$ ), 7.3 (s, $4 \mathrm{H}$, aromatic protons), and 7.4-8.2 (m, $8 \mathrm{H}$, aromatic protons).

Anal. Calcd for $\mathrm{C}_{24} \mathrm{H}_{20} \mathrm{~N}_{2} \mathrm{O}_{8} \mathrm{~S}_{2}$ : C, 54.54\%; H, 3.81\%; N, $5.30 \%$. Found: C, $54.49 \%$;, $3.90 \%$; N, $5.03 \%$.

\section{Synthesis of Ethylene Glycol Bis[(2-nitrobenzyloxycar- bonyl)thioethyl]ether}

The reaction of $1.82 \mathrm{~g}(10 \mathrm{mmol})$ of EBME with $5.93 \mathrm{~g}$ $(24 \mathrm{mmol})$ of NBCI was performed in DMF $(100 \mathrm{~mL})$ in the presence of $2.42 \mathrm{~g}(24 \mathrm{mmol})$ of triethylamine (TEA) at $50^{\circ} \mathrm{C}$ for $24 \mathrm{~h}$ under nitrogen, and the DMF was evaporated. The mixture was diluted with carbon tetrachloride, washed with water and $0.1-N$ of $\mathrm{NaOH}$ aqueous solution, and dried with $\mathrm{MgSO}_{4}$ overnight. Carbon tetrachloride was evaporated from the solution. The yield of ethylene glycol bis[(2-nitrobenzyloxycarbonyl)thioethyl]ether (EBTE) was $4.22 \mathrm{~g}(78 \%)$. mp $70-71^{\circ} \mathrm{C}$. IR (KBr): $1712(\mathrm{C}=\mathrm{O}), 1527$ and 1342 $\left(-\mathrm{NO}_{2}\right)$, and $1132 \mathrm{~cm}^{-1}(\mathrm{C}-\mathrm{O}-\mathrm{C})$. UV (in THF): $258 \mathrm{~nm}$. ${ }^{1} \mathrm{H}$ NMR $\left(200 \mathrm{MHz}, \mathrm{CDCl}_{3}, \mathrm{TMS}\right): \delta=3.1 \quad(\mathrm{t}, J=$ $\left.6.4 \mathrm{~Hz}, 4 \mathrm{H}, \mathrm{O}-\mathrm{CH}_{2}-\mathrm{CH}_{2}-\mathrm{S}\right), 3.6\left(\mathrm{~s}, 4 \mathrm{H}, \mathrm{O}-\mathrm{CH}_{2}-\mathrm{CH}_{2}-\right.$ ), $3.7\left(\mathrm{t}, J=6.4 \mathrm{~Hz}, \overline{4 \mathrm{H}}, \mathrm{O}-\mathrm{CH}_{2}-\mathrm{CH}_{2}-\mathrm{S}\right), 5.7(\mathrm{~s}, 4 \mathrm{H}$, $\left.\mathrm{CH}_{2}-\mathrm{O}\right), 7.3-8.2(\mathrm{~m}, 8 \mathrm{H}$, aromatic protons).

Anal. Calcd for $\mathrm{C}_{22} \mathrm{H}_{24} \mathrm{~N}_{2} \mathrm{O}_{10} \mathrm{~S}_{2}: \mathrm{C}, 48.88 \% ; \mathrm{H}$, $4.48 \%$; N, 5.18\%. Found: C, 48.61\%; H, 4.41\%; N, $5.36 \%$.

\section{Typical Procedure for Photo-generation of Dithiol in Solution}

An XBBTC solution $\left(0.03 \mathrm{~mol} \mathrm{~L}^{-1}\right)$ in THF $(30 \mathrm{~mL})$ was charged into a small cylindrical quartz reactor with a water jacket and thermometer. Nitrogen gas was bubbled through the solution for $30 \mathrm{~min}$ before UV irradiation. Photolysis of the XBBTC was carried out using a 500-W high-pressure mercury lamp (Ushio Electric Co., USH-500D) with thermal-ray filter (HA-50) under nitrogen atmosphere at $30^{\circ} \mathrm{C}$ for $6 \mathrm{~h}$. During photo-irradiation, the intensity of the incident light was kept always at $1.92-1.98 \mathrm{~mW} \mathrm{~cm}^{-2}$ (at $310 \mathrm{~nm}$ ). The THF was evaporated in vacuo. The ${ }^{1} \mathrm{H}$ NMR spectrum (in $\mathrm{CDCl}_{3}$ ) of the dried reaction mixture showed decrease $(29 \%)$ of methylene protons at $\delta=4.1$ and 5.7 ppm due to XBBTC molecules, and new appearance $(15 \%)$ of methylene protons (doublet) at $\delta=3.7 \mathrm{ppm}$ and free thiol protons (triplet) at $\delta=1.8 \mathrm{ppm}$ due to the BMMB.

\section{Typical Procedure for Photolysis of Blocked Dithiol in Epoxy Resin and Thermal Curing Reaction of Epoxy Resin with Photo-generated Dithiol}

The rates of photolysis of XBBTC and thermal curing reaction of the epoxy resin were measured as follows. Epicoat $828(0.38 \mathrm{~g} ; 1 \mathrm{mmol})$ and XBBTC $(0.53 \mathrm{~g} ; 1$ $\mathrm{mmol}$ ) were mixed in an agate mortar, and the mixture was cast on a $\mathrm{KBr}$ plate. The mixture on the plate was irradiated by a $250-\mathrm{W}$ high-pressure mercury lamp (Ushio Electric Co., USH-250D) without a filter under nitrogen atmosphere. The intensity of the incident light was kept at $0.45 \mathrm{~mW} \mathrm{~cm}^{-2}$ (at $310 \mathrm{~nm}$ ). Decreasing rates of the $\mathrm{C}=\mathrm{O}$ group at $1709 \mathrm{~cm}^{-1}$ due to the $\mathrm{XBBTC}$ and cyclic $\mathrm{C}-\mathrm{O}-\mathrm{C}$ group at $910 \mathrm{~cm}^{-1}$ due to the epoxy resin were measured by IR spectroscopy. The rate of decrease of the epoxide group at $910 \mathrm{~cm}^{-1}$ in the mixture on the same $\mathrm{KBr}$ plate on heating at $120^{\circ} \mathrm{C}$ was monitored.

\section{Photolysis of Blocked Dithiol in PGMA Film and Thermal Curing Reaction of PGMA Film with Photo-generated Dithiol}

PGMA $(0.18 \mathrm{~g} ; 1 \mathrm{mmol}$ as epoxide group) and EBTE $(0.27 \mathrm{~g} ; 0.5 \mathrm{mmol})$ were dissolved in small amounts of THF. The solution was cast on a $\mathrm{KBr}$ plate and dried to make a polymer film on the plate. The film on the plate was irradiated under the same conditions applied for the reaction of epoxy resin with XBBTC above.

\section{RESULTS AND DISCUSSION}

\section{Synthesis of Blocked Dithiols}

Reaction conditions for the synthesis of the intermediate NBCI were examined in detail, and crude NBCI was obtained in 53, 48, and $44 \%$ yields in THF at room temperature for $3 \mathrm{~h}$, in dichloromethane at $50^{\circ} \mathrm{C}$ for $19 \mathrm{~h}$, and in acetonitrile at room temperature for $24 \mathrm{~h}$, respectively, when the reaction of 2-nitrobenzyl alcohol with $N, N^{\prime}$-carbonyldiimidazole was carried out on a small scale. Based on the above conditions, the reaction was performed on a preparative scale, and the targeted NBCI was synthesized with good yield $(78 \%)$ in acetonitrile at room temperature for $24 \mathrm{~h}$ (see Experimental part). This indicates that the reaction of 2-nitrobenzyl alcohol with $N, N^{\prime}$-carbonyldiimidazole proceeds very smoothly in various organic solvents (Scheme 1).

The reaction of NBCI with BMMB was examined on 


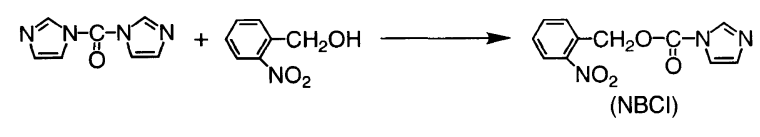

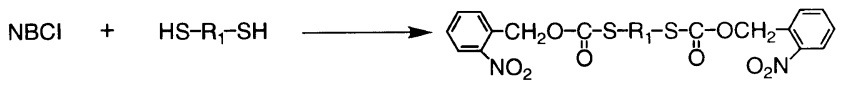

$\mathrm{R}_{1}:-\mathrm{CH}_{2}-\mathrm{CH}_{2}-(\mathrm{BMMB}, \mathrm{XBBTC}),-\mathrm{CH}_{2} \mathrm{CH}_{2} \mathrm{OCH}_{2} \mathrm{CH}_{2} \mathrm{OCH}_{2} \mathrm{CH}_{2}-(\mathrm{EBME}, \mathrm{EBTE})$

Scheme 1.

Table I. Reactions of dithiol with $\mathrm{NBCI}^{\mathrm{a}}$

\begin{tabular}{|c|c|c|c|c|c|}
\hline \multirow{2}{*}{$\begin{array}{c}\text { Run } \\
\text { no. }\end{array}$} & \multirow{2}{*}{ Dithiol } & \multirow{2}{*}{ Solvent } & Temp & Time & Yield \\
\hline & & & ${ }^{\circ} \mathrm{C}$ & $\mathrm{h}$ & $\%$ \\
\hline 1 & $\mathrm{BMMB}^{\mathrm{a}}$ & Acetonitrile & 50 & 2 & 0 \\
\hline 2 & $\mathrm{BMMB}^{\mathrm{a}}$ & DMF & Room temp & 3 & 0 \\
\hline 3 & $\mathrm{BMMB}^{\mathrm{a}}$ & DMF & 50 & 0.5 & 88 \\
\hline 4 & $\mathrm{BMMB}^{\mathrm{a}}$ & $\mathrm{DMF}$ & 70 & 4 & 85 \\
\hline 5 & $\mathrm{BMMB}^{\mathrm{a}}$ & DMF & 70 & 12 & 87 \\
\hline 6 & $\mathrm{EBME}^{\mathrm{b}}$ & DMF & 50 & 24 & 53 \\
\hline 7 & $\mathrm{EBME}^{\mathrm{c}}$ & DMF & 50 & 24 & 76 \\
\hline
\end{tabular}

${ }^{\text {a }}$ Reaction was carried out with $4 \mathrm{mmol}$ of $\mathrm{NBCI}$ and $2 \mathrm{mmol}$ dithiol in the solvent $(20 \mathrm{~mL}) . \quad{ }^{\mathrm{b}}$ Reaction was carried out with $4.8 \mathrm{mmol}$ of $\mathrm{NBCI}$ and $2 \mathrm{mmol}$ of dithiol in the solvent $(20 \mathrm{~mL})$. ${ }^{\mathrm{c}}$ Reaction was carried out in the presence of TEA $(4.8 \mathrm{mmol})$ as a base.

a small scale to obtain blocked thiol XBBTC. As summarized in Table I, although the reaction occurred very smoothly in $\mathrm{DMF}$ at $50^{\circ} \mathrm{C}$ for only $30 \mathrm{~min}$ to give XBBTC in $88 \%$ yield, the reaction did not proceed in acetonitrile at $50^{\circ} \mathrm{C}$ for $2 \mathrm{~h}$. The reaction of NBCI with $\mathrm{BMMB}$ proceeded to give XBBTC in good yield in DMF under various reaction conditions (Scheme 1). Based on these data, the reaction of NBCI with BMMB was performed on a preparative scale, and the targeted XBBTC was obtained in $70 \%$ yield in DMF at $50^{\circ} \mathrm{C}$ for $30 \mathrm{~min}$.

Blocked dithiol EBTE was obtained in 53\% yield when the reaction of $\mathrm{NBCI}$ with EBME was carried out in $\mathrm{DMF}$ at $50^{\circ} \mathrm{C}$ for $24 \mathrm{~h}$. It seems that the reactivity of EBME to NBCI was lower than that of BMMB. However, the yield of EBTE increased to $77 \%$ when the reaction was performed using triethylamine as a base under the same conditions.

\section{Photolysis of Blocked Dithiol in THF Solution}

Photolysis of blocked dithiol XBBTC was carried out in THF solution in a cylindrical quartz reactor under UV-irradiation using a 500-W high-pressure mercury lamp. As shown in Figure 1, XBBTC decomposed gradually under UV-irradiation. The reaction proceeded with 29 and $32 \%$ conversions, as determined by the intensity ratio of proton signals at $5.7 \mathrm{ppm}$ due to methylene protons $v s$. aromatic protons at 7.4-8.2 ppm, after 6 and $12 \mathrm{~h}$ irradiation under nitrogen atmosphere, respectively (Figure 1). After $29 \mathrm{~mol} \%$ of methylene protons at $\delta=4.1$ and $5.7 \mathrm{ppm}$ due to the XBBTC had been reduced by the irradiation for $6 \mathrm{~h}$, the ${ }^{1} \mathrm{H}$ NMR spectrum showed a new peak $(15 \mathrm{~mol} \%)$ of free thiol protons at $\delta=1.8 \mathrm{ppm}$ due to $\mathrm{BMMB}$. This shows that photo-deprotection of XBBTC to produce BMMB

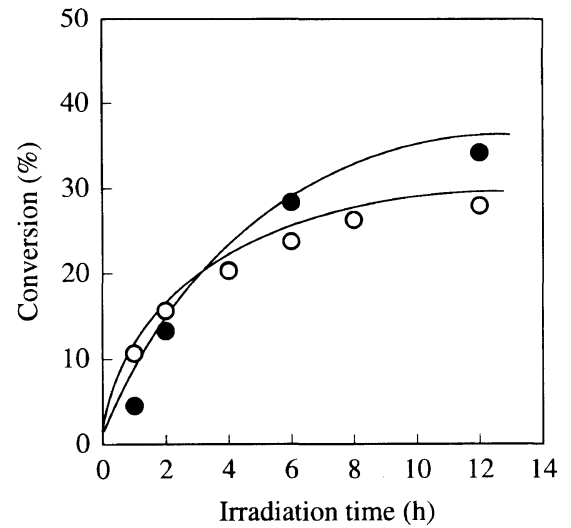

Figure 1. Rates of photolysis of blocked dithiols in THF solution. (O) XBВTC; (О) EBTE.

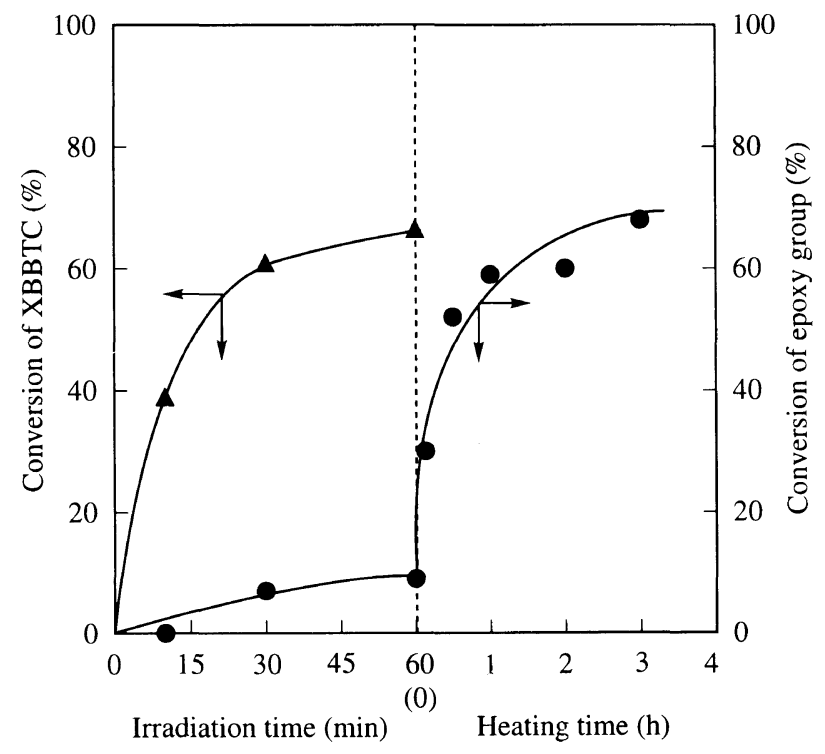

Figure 2. Rates of photochemical reaction of XBBTC in bisphenoltype epoxy resin and addition reactions of the epoxy group with photo-generated BMMB. ( $\boldsymbol{\Delta})$ conversion of $\mathrm{C}=\mathrm{O}$ group; $(\boldsymbol{O})$ conversion of cyclic ether.

occurred under UV-irradiation in nitrogen. However, it seems that the thiol groups in the BMMB were partly lost in subsequent side-reactions.

When the photochemical reaction of EBTE was performed in THF solution under the same irradiation conditions, the proton signal at $5.7 \mathrm{ppm}$ due to the methylene protons of EBTE clearly decreased and new proton signals at $1.8 \mathrm{ppm}$ and $2.7 \mathrm{ppm}$ due to free thiol proton and methylene protons from free dithiol EBME appeared. The degree of conversion of EBTE was determined from the intensity ratio of methylene protons at $5.7 \mathrm{ppm} v \mathrm{~s}$. aromatic protons at $7.3-8.2 \mathrm{ppm}$ (Figure 1). This means that the photo-deprotection of EBTE also proceeds in the THF solution mostly the same conversions as with XBBTC.

Photolysis of Blocked Dithiol in Epoxy Resin and Thermal Curing Reaction of Epoxy Resin with Photo-generated Dithiol

The photolysis of XBBTC in bisphenol-type epoxy resin (Epicoat 828) followed by the thermal curing reaction of the epoxy resin were performed on a $\mathrm{KBr}$ plate. As shown in Figure 2, the conversion of XBBTC 


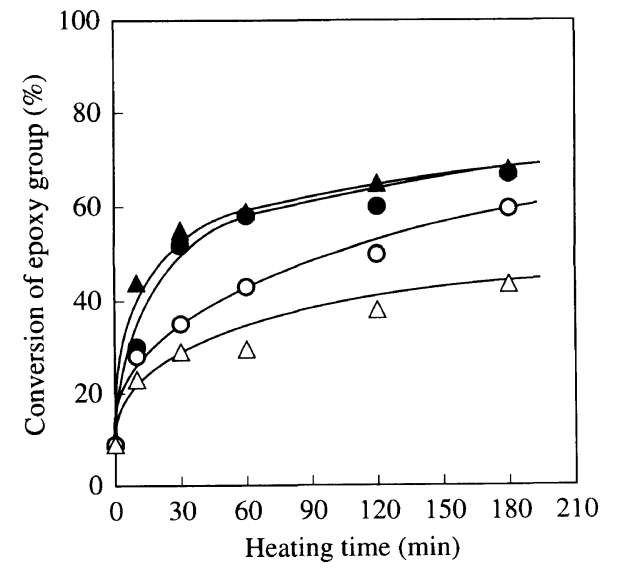

Figure 3. Rates of thermal curing reaction of the epoxy groups in the mixture of bisphenol-type epoxy resin with photo-generated BMMB. $(\triangle)$ at $80^{\circ} \mathrm{C} ;(\bigcirc)$ at $100^{\circ} \mathrm{C} ;(\bigcirc)$ at $120^{\circ} \mathrm{C} ;(\Delta)$ at $140^{\circ} \mathrm{C}$.

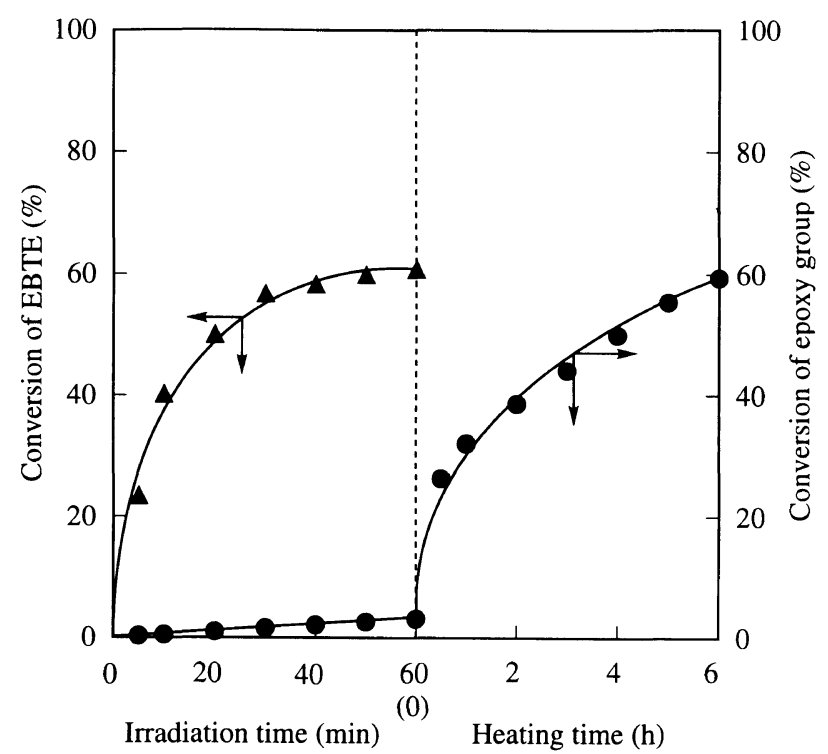

Figure 4. Rates of photochemical reaction of EBTE in bisphenoltype epoxy resin and addition reactions of the epoxy group with photo-generated EBME. ( $\boldsymbol{\Delta})$ conversion of $\mathrm{C}=\mathrm{O}$ group; $(\boldsymbol{O})$ conversion of cyclic ether.

to $\mathrm{BMMB}$ and the degree of ring opening of the epoxide group were confirmed by the IR spectrum. The absorption peak at $1709 \mathrm{~cm}^{-1}$ due to the $\mathrm{C}=\mathrm{O}$ stretching decreased, and $67 \%$ conversion was obtained after UV-irradiation for $1 \mathrm{~h}$. A small decrease of the absorption peak at $910 \mathrm{~cm}^{-1}$ due to the epoxide group was also found. This indicates that a small amount of the epoxide group reacted with the produced free thiol groups in BMMB during UV-irradiation. Although the degree of conversion of the epoxide group was only $9 \%$ after UV-irradiation for $1 \mathrm{~h}$, the conversion of the epoxide group in the mixture increased very rapidly with heating at $120^{\circ} \mathrm{C}$, and the conversion reached $67 \%$ after $3 \mathrm{~h}$. A new absorption peak due to a hydroxyl group also appeared at $3300 \mathrm{~cm}^{-1}$. This means that photo-generated free thiol groups in BMMB reacted with the same amount of the epoxy group in the resin (Scheme 2).

The mixture of XBBTC with the same epoxy resin was irradiated with UV light for $1 \mathrm{~h}$, and then the mixture was heated under various temperatures. As shown in
Figure 3, the rate of conversion of the epoxide group in the mixture increased with the temperature. This shows that the thermal curing reaction of epoxy resin using photo-generated free thiol compound was also strongly affected by reaction temperature.

When a mixture of blocked dithiol EBTE with the same type epoxy resin was irradiated for $1 \mathrm{~h}$ under the same conditions as with the above reaction, conversions of EBTE and the epoxide group in the mixture were $61 \%$ and $3 \%$, respectively. Conversion of the epoxide group in the photo-irradiated mixture reached $59 \%$ by heating at $120^{\circ} \mathrm{C}$ for $6 \mathrm{~h}$ (Figure 4). This indicates that free dithiol compound EBME was produced smoothly in the epoxy resin by the UV-irradiation and the produced thiol groups reacted quantitatively with the epoxide groups in the resin, although the reactivity of EBME to the epoxy resin was lower than that of BMMB.

The reaction products of bisphenol-type epoxy resin with photo-generated BMMB or EBME were soluble in chloroform and THF after UV-irradiation for $1 \mathrm{~h}$, followed by heating at $120^{\circ} \mathrm{C}$ for $3 \mathrm{~h}$ or $6 \mathrm{~h}$, respectively. This means that the reaction of bisphenol-type epoxy resin with the photo-generated BMMB or EBME produced linear polymers or oligomers as shown in Scheme 2 , where $n$ is the degree of polymerization.

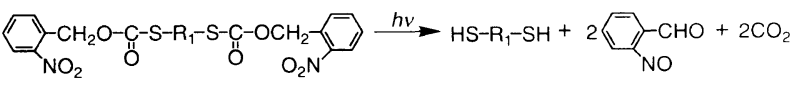

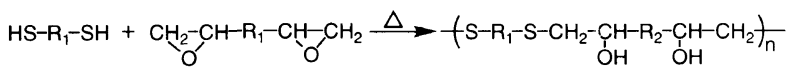

$$
\begin{aligned}
& \mathrm{R}_{1} \text { : }-\mathrm{CH}_{2}-\left(-\mathrm{CH}_{2}-(\mathrm{BMMB}, \mathrm{XBBTC}),-\mathrm{CH}_{2} \mathrm{CH}_{2} \mathrm{OCH}_{2} \mathrm{CH}_{2} \mathrm{OCH}_{2} \mathrm{CH}_{2}-\right.\text { (EBME, EBTE) }
\end{aligned}
$$

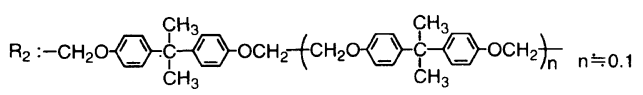

Scheme 2.

Since gel products were not obtained from the reaction of the mixture of bisphenol-type epoxy resin with photo-generated BMMB or EBME, the photochemical reaction of novolac-type epoxy resin (DEN 438) containing three or more epoxy groups in the molecule with XBBTC was performed under the same conditions. As shown in Figure 5, the conversions of XBBTC and epoxide group of the resin in the mixture were $74 \%$ and $11 \%$, respectively, after UV-irradiation for $1 \mathrm{~h}$ at room temperature. The degree of conversion of the epoxide group in the mixture increased by heating at $120^{\circ} \mathrm{C}$, and reached $69 \%$ after thermal treatment for $3 \mathrm{~h}$. A mixture of the novolac-type epoxy resin with XBBTC became insoluble in chloroform or THF after UV-irradiation for $1 \mathrm{~h}$, followed by heating at $120^{\circ} \mathrm{C}$ for $3 \mathrm{~h}$ (Scheme 3 ).

As shown in Figure 6, the conversion of EBTE in the mixture with the same type epoxy resin was about $60 \%$ after the irradiation for $60 \mathrm{~min}$, and the thermal curing reaction of the epoxy resin using the photo-generated EBME also proceeded with $61 \%$ conversion by heating at $120^{\circ} \mathrm{C}$ for $6 \mathrm{~h}$. This reaction product was also insoluble in chloroform and THF. 


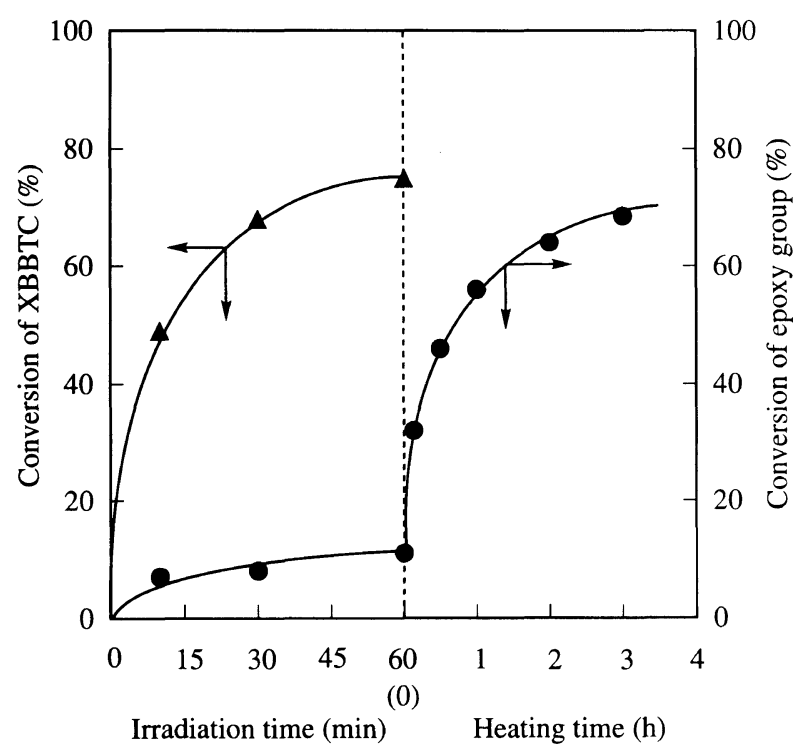

Figure 5. Rates of photochemical reaction of XBBTC in novolactype epoxy resin and addition reactions of the epoxy group with photo-generated BMMB. ( $\Delta$ ) conversion of $\mathrm{C}=\mathrm{O}$ group; (O) conversion of cyclic ether.

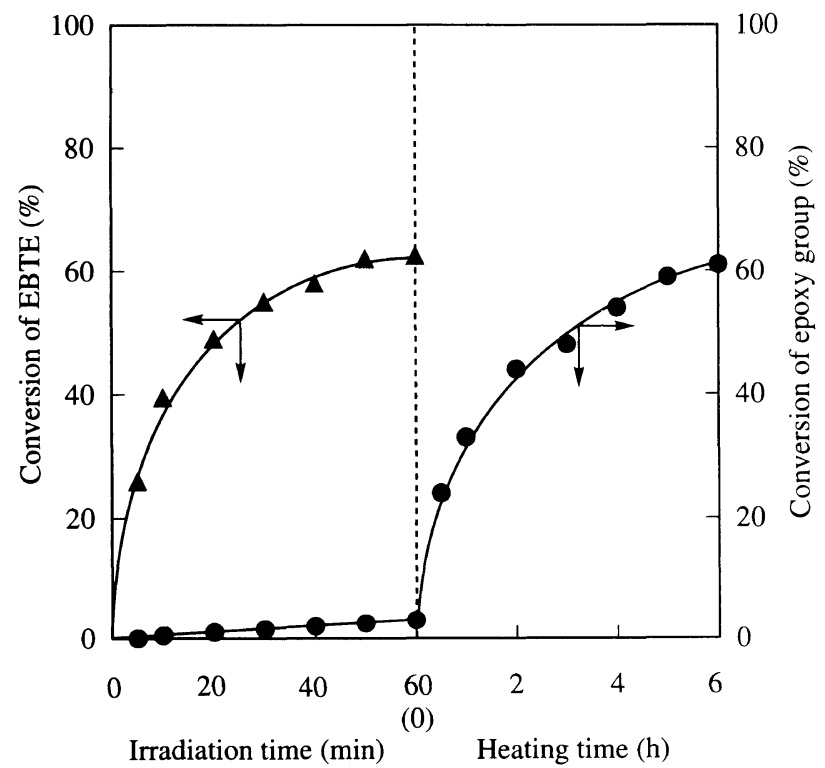

Figure 6. Rates of photochemical reaction of EBTE in novolac-type epoxy resin and addition reactions of the epoxy group with photogenerated EBME. ( $\boldsymbol{\Delta}$ ) conversion of $\mathrm{C}=\mathrm{O}$ group; $(\boldsymbol{O})$ conversion of cyclic ether.

These results indicate that thermal curing reaction of novolac-type epoxy resin with the photo-generated BMMB or EBME occurs to produce the corresponding gel products as shown in Scheme 3, where $n$ is the degree of polymerization.
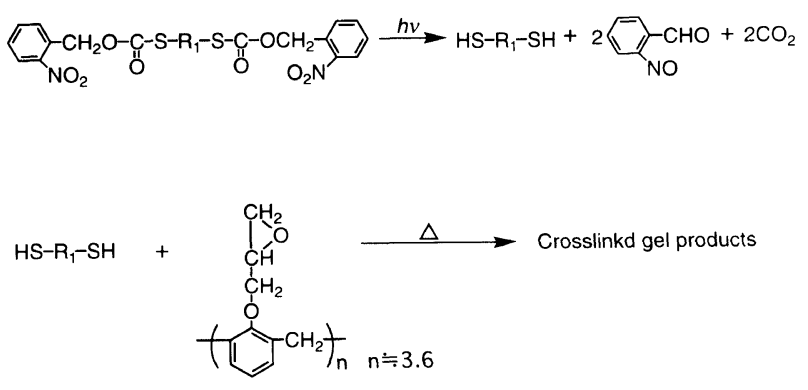

Scheme 3 .

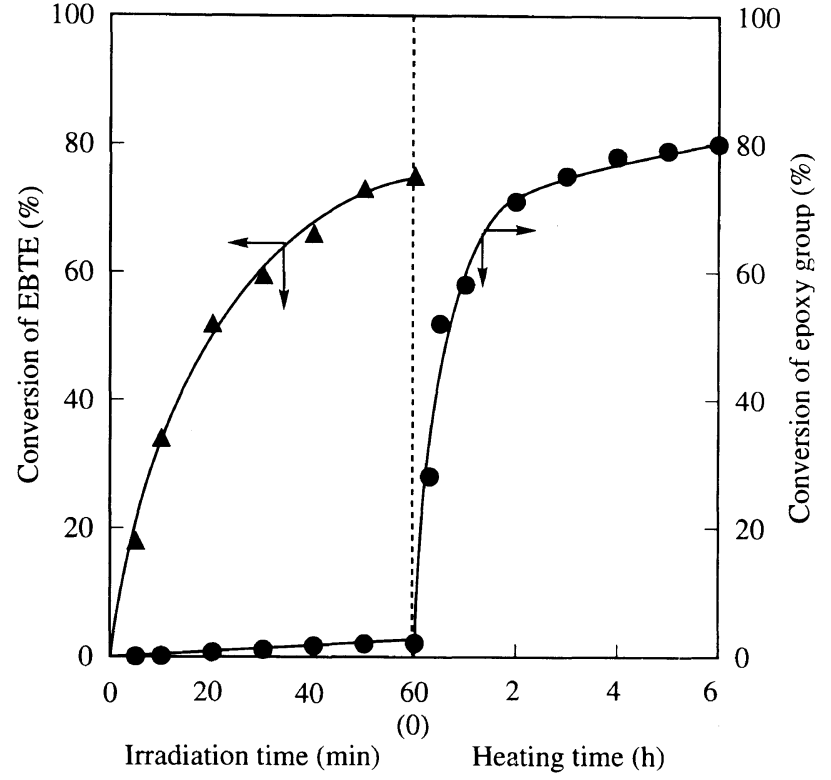

Figure 7. Rates of photochemical reaction of EBTE in PGMA and addition reactions of the pendant epoxy group with photo-generated EBME. ( $\Delta$ ) conversion of $\mathrm{C}=\mathrm{O}$ group; ( $)$ conversion of cyclic ether.

The photolysis of EBTE was examined in PGMA film. As shown in Figure 7, the conversion of EBTE increased with time and reached $75 \%$ by the UV-irradiation for $1 \mathrm{~h}$. This value was much higher than that of the reaction of EBTE in the mixture of epoxy resins. It seems that the transparency of the mixture of blocked dithiol with the resin strongly affected the reaction, and EBTE in PGMA film with good transparency showed high photochemical reactivity. The conversion of the pendant epoxide group of PGMA film containing photo-generated free dithiol EBME increased with heating time, and reached about $80 \%$ after thermal treatment at $160^{\circ} \mathrm{C}$ for $6 \mathrm{~h}$, although the reaction of the pendant epoxide group of the film barely proceeded at $120^{\circ} \mathrm{C}$. This shows that the reactivity of the pendant epoxide group in PGMA film to the photo-generated free thiol groups was lower than that of the epoxide groups of low molecular weight epoxy resins to the photo-generated free thiol groups. The polymer film composed from PGMA with EBTE became insoluble in chloroform or THF after UVirradiation for $1 \mathrm{~h}$ followed by heating at $160^{\circ} \mathrm{C}$ for $6 \mathrm{~h}$. This means that photo-generated dithiol compound can also be used as a thermal crosslinking reagent of the copolymers containing pendant epoxide groups (Scheme 4).

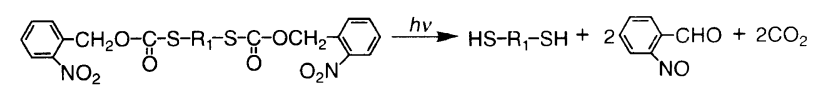

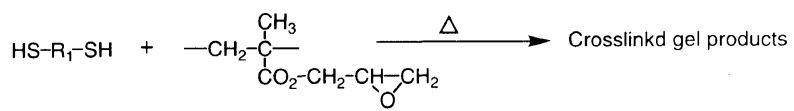

Scheme 4. 


\section{REFERENCES}

1. For example: a) H. Kakiuchi, Ed., "Epoxy Resins," Shokodo, Tokyo, 1985; b) R. S. Bauer, Ed., "Epoxy Resin Chemistry," ACS Symposium Series, No. 114, The American Chemical Society, Washington, D.C., 1976; c) R. S. Bauer, Ed., "Epoxy Resin Chemistry II," ACS Symposium Series, No. 221, The American Chemical Society, Washington, D.C., 1983; d) K. Iwata, "Polyurethane Resin Handbook," Nikkan Kogyo Shinbun, Tokyo, 1987.

2. M. R. Winkle and K. A. Graziano, J. Photopolym. Sci. Technol., 3, 419 (1990).

3. C. Kutal and C. G. Willson, J. Electrochem. Soc., 134, 2280 (1987).
4. K. Ito, M. Nishimura, M. Sashio, and M. Tsunooka, Chem. Lett. 1153 (1992).

5. a) J. F. Cameron and J. M. J. Frechet, J. Org. Chem., 55, 5919 (1990); b) J. F. Cameron and J. M. J. Frechet, J. Am. Chem. Soc., 113, 4303 (1991); c) J. M. J. Frechet, Pure Appl. Chem., 64, 1239 (1992).

6. a) T. Nishikubo, E. Takehara, and A. Kameyama, Polym. J., 25, 421 (1993); b) T. Nishikubo, E. Takehara, and A. Kameyama, J. Polym. Sci., Part A, Polym. Chem., 31, 3013 (1993).

7. T. Nishikubo, A. Kameyama, and K. Kashiwagi, Polym. J., 26 864 (1994).

8. T. Nishikubo, T. Kawashima, and S. Watanabe, J. Polym. Sci., Part A, Polym. Chem., 31, 1659 (1993). 